\title{
Treatment effectiveness and treatment patterns among rheumatoid arthritis patients after switching from a tumor necrosis factor inhibitor to another medication
}

\author{
This article was published in the following Dove Press journal: \\ ClinicoEconomics and Outcomes Research \\ 2 December 2016 \\ Number of times this article has been viewed
}

\author{
Machaon MK Bonafede' \\ Jeffrey R Curtis ${ }^{2}$ \\ Donna McMorrow' \\ Puneet Mahajan ${ }^{3}$ \\ Chieh-I Chen ${ }^{4}$ \\ 'Outcomes Research, Truven \\ Health Analytics, Cambridge, MA, \\ ${ }^{2}$ Division of Clinical Immunology \\ and Rheumatology, University of \\ Alabama at Birmingham, Birmingham, \\ AL, ${ }^{3}$ Health Economics and Outcomes \\ Research, Sanofi, Bridgewater, NJ, \\ ${ }^{4} \mathrm{Health}$ Economics and Outcomes \\ Research, Regeneron Pharmaceuticals, \\ Inc., Tarrytown, NY, USA
}

\begin{abstract}
Objectives: After treatment failure with a tumor necrosis factor inhibitor (TNFi), patients with rheumatoid arthritis (RA) can switch to another TNFi (TNFi cyclers) or to a targeted diseasemodifying antirheumatic drug (DMARD) with a non-TNFi mechanism of action (non-TNFi switchers). This study compared treatment patterns and treatment effectiveness between TNFi cyclers and non-TNFi switchers in patients with RA.
\end{abstract}

Methods: The analysis included a cohort of patients from the Truven Health Analytics MarketScan Commercial database with RA who switched from a TNFi (adalimumab, certolizumab pegol, etanercept, golimumab, or infliximab) either to another TNFi or to a non-TNFi targeted DMARD (abatacept, tocilizumab, or tofacitinib) between January 1, 2010 and September 30, 2014. A claims-based algorithm was used to estimate treatment effectiveness based on six criteria (adherence, no dose increase, no new conventional therapy, no switch to another targeted DMARD, no new/increased oral glucocorticoid, and intra-articular injections on $<2$ days).

Results: The cohort included 5,020 TNFi cyclers and 1,925 non-TNFi switchers. Non-TNFi switchers were significantly less likely than TNFi cyclers to switch therapy again within 6 months $(13.2 \%$ vs $19.5 \% ; P<0.001)$ or within 12 months $(29.7 \%$ vs $34.6 \% ; P<0.001)$ and significantly more likely to be persistent on therapy at 12 months $(61.8 \%$ vs $58.2 \% ; P<0.001)$. Non-TNFi switchers were significantly more likely than TNFi cyclers to achieve all six of the claims-based effectiveness algorithm criteria for the 12 months after the initial switch $(27 \%$ vs $24 \% ; P=0.011)$.

Conclusion: Although the absolute differences were small, these results support switching to a non-TNFi targeted DMARD instead of TNFi cycling when patients with RA require another therapy after TNFi failure.

Keywords: rheumatoid arthritis, biologic, switching, tumor necrosis factor inhibitor

\section{Introduction}

The use of a biologic disease-modifying antirheumatic drug (DMARD) or the targeted synthetic DMARD tofacitinib is recommended for patients with rheumatoid arthritis (RA) who have moderate or high disease activity despite monotherapy with a conventional synthetic DMARD. ${ }^{1-3}$ The most commonly used biologics in these patients are the tumor necrosis factor inhibitors (TNFis) etanercept, adalimumab, and infliximab; newer TNFi (certolizumab pegol and golimumab) are used less frequently. ${ }^{4}$ After an adequate trial (generally for $\geq 3$ months) of a TNFi, switching to another drug is recommended if disease activity is moderate or high because of
Correspondence: Machaon MK Bonafede Truven Health Analytics, 150 Cambridge Park Drive, Cambridge, MA 02I40, USA Tel + I 6035805587

Email machaon.bonafede@truvenhealth. com 
lack of response or loss of clinical benefit from the initial TNFi. ${ }^{1-3}$ Patients who fail TNFi therapy can switch either to another TNFi (TNFi cyclers) or to a non-TNFi mechanism of action such as the biologics abatacept, rituximab, or tocilizumab or the targeted synthetic DMARD tofacitinib (non-TNFi switchers).

In clinical practice, a majority of RA patients switch from the first TNFi to another TNFi, the so-called TNFi cyclers. ${ }^{5-11}$ However, the evidence to support TNFi cycling is limited, ${ }^{12-15}$ and some studies have suggested that switching to a non-TNFi biologic is more effective than TNFi cycling. ${ }^{6,16-18}$ Additional studies are needed, ${ }^{19}$ particularly as newer non-TNFi options such as sarilumab, ${ }^{20,21}$ sirukumab, ${ }^{22}$ and baricitinib ${ }^{23-25}$ are expected to become available soon for RA treatment. ${ }^{26,27}$

Prospective, randomized, controlled clinical studies could provide definitive evidence of the comparative effectiveness of different treatment approaches in these patients, but there are barriers to conducting these studies. Controlled clinical studies tend to have highly selective eligibility criteria that exclude complicated patients, ${ }^{28}$ so it could be difficult to recruit RA patients with moderate or high disease activity who require a switch in therapy. Additionally, the costs and resources required to conduct an adequately powered, prospective comparison of all available drug sequences would be prohibitive.

In the absence of prospective clinical studies, retrospective claims analysis can be used not only to evaluate treatment patterns such as biologic switching or treatment persistence but also to provide estimates for clinical outcomes. One such approach developed and validated a claims-based effectiveness algorithm that uses administrative data as a proxy for clinical response as measured by the Disease Activity Score in 28 joints (DAS28). ${ }^{29}$ This algorithm estimates treatment effectiveness for RA by combining six measures from claims that include treatment adherence and dosing, use of concomitant drugs (conventional synthetic DMARDs and glucocorticoids), and switching to another targeted DMARD. The algorithm was developed and validated against registry data in a Veterans Administration population ${ }^{29}$ and has been applied to estimate treatment effectiveness for targeted DMARDs in claims databases for commercially insured, ${ }^{4,30-33}$ Medicare, ${ }^{34}$ and Medicaid ${ }^{35}$ patients.

The objective of this study was to compare treatment patterns (switching patterns and persistence) and treatment effectiveness (according to the algorithm discussed earlier) between TNFi cyclers and non-TNFi switchers in patients with RA in a large, commercially insured population.

\section{Methods}

\section{Patient selection criteria}

Medical and pharmacy claims were analyzed from the MarketScan ${ }^{\circledR}$ Commercial database (Truven Health Analytics Inc., Ann Arbor, MI). This database contains inpatient and outpatient medical claims and outpatient pharmacy claims for $\sim 35$ million employees and their dependents annually, covered under a variety of fee-for-service and managed care health plans. No identifiable protected health information was extracted or accessed during the study, pursuant to the United States Health Insurance Portability and Accountability Act (HIPAA). Because the study did not involve the collection, use, or transmittal of individually identifiable data, and due to the compliance of this study with HIPAA, patient consent and institutional review board approval to conduct this study were not necessary.

This analysis included a cohort of patients who received at least one TNFi (adalimumab, certolizumab pegol, etanercept, golimumab, or infliximab) or non-TNFi (abatacept, tocilizumab, or tofacitinib) between January 1, 2010 and September 30,2014 . The index claim for each patient was the patient's first claim for a new TNFi or non-TNFi in this period. To identify patients who switched to a new therapy on the index date, each patient in the analysis was continuously enrolled with medical and pharmacy coverage for at least 12 months before the index date (the pre-index period), had at least one claim for a different TNFi in the pre-index period, and had no claim for the index drug in the pre-index period. On the index date, the patients could only have one claim for a TNFi or non-TNFi. The patients were required to be at least 18 years of age on the index date and have at least 12 months of continuous medical and pharmacy coverage post-index. Thus, claims through September 30, 2015, were included in the analysis.

All patients in the analysis had RA, which was identified by at least one non-diagnostic medical claim with an International Classification of Diseases, Ninth Revision, Clinical Modification (ICD-9-CM) code of 714.0x in the primary or secondary position in the 12 months pre-index or the first 30 days post-index. Patients were not included in the analysis if they had any non-diagnostic claims within 12 months pre-index or 30 days post-index for another condition for which at least one of the targeted DMARDs was indicated: ankylosing spondylitis (ICD-9-CM 720.0), Crohn's disease (ICD-9-CM 555.x), juvenile idiopathic arthritis (ICD-9-CM 714.3), plaque psoriasis (ICD-9-CM 696.1x), psoriatic arthritis (ICD-9-CM 696.0), ulcerative colitis (ICD9-CM 556.x), chronic lymphocytic leukemia (ICD-9-CM 204.1x), or non-Hodgkin's lymphoma (ICD-9-CM 200.xx, 202.xx). Rituximab was not included in the analysis because 
adherence and treatment effectiveness could not be assessed for rituximab using the claims-based effectiveness algorithm.

\section{Statistical analysis}

The results were analyzed for all patients combined and for TNFi cyclers and non-TNFi switchers separately. Analyses of treatment patterns included the proportion of patients who switched therapy again to another TNFi or non-TNFi within 6 months post-index or within 12 months post-index, as well as the proportion of patients who were persistent on the index therapy without switching or discontinuing treatment with a gap of at least 60 days during the 12-month post-index period. A validated claims-based algorithm ${ }^{29}$ was applied to the data to estimate treatment effectiveness. To be considered effectively treated with the index therapy, a patient needed to satisfy all six of the following algorithm criteria:

1. Adherence to the index therapy

a. for self-administered drugs: for subcutaneous abatacept, adalimumab, certolizumab pegol, etanercept, golimumab, and tocilizumab, as well as oral tofacitinib, a proportion of days covered (PDC) of at least $80 \%$ using the expected duration of clinical benefit

b. for infused drugs: for intravenous abatacept, golimumab, and tocilizumab, a PDC of at least $80 \%$ using the expected duration of clinical benefit, and for intravenous infliximab, at least as many infusions as the lower end of the recommended dosing schedule in the product labeling

2. No increase in the targeted DMARD dose

a. abatacept (intravenous): no increase $\geq 100 \mathrm{mg}$ from the first to last dose

b. abatacept (subcutaneous): no dose $\geq 250 \mathrm{mg} /$ week post-index

c. adalimumab (subcutaneous): no dose $\geq 40 \mathrm{mg} /$ week post-index

d. certolizumab pegol (subcutaneous): no dose $\geq 200 \mathrm{mg}$ / week after post-index day 56

e. etanercept (subcutaneous): no dose $\geq 100 \mathrm{mg} /$ week post-index

f. golimumab (intravenous): no increase $\geq 50 \mathrm{mg}$ from the first to last dose

g. golimumab (subcutaneous): no dose $\geq 25 \mathrm{mg} /$ week post-index (ie, $>50 \mathrm{mg}$ monthly post-index)

h. infliximab: no increase $\geq 100 \mathrm{mg}$ from the first to last dose, $<11$ infusion dates post-index, and $\geq 7$ weeks between doses (after the third dose)

i. tocilizumab (intravenous): no increase greater than or equal to twofold from the first to the last dose j. tocilizumab (subcutaneous): if the starting dose was not $162 \mathrm{mg} /$ week, no dose $\geq 162 \mathrm{mg}$ /week postindex; if the starting dose was $162 \mathrm{mg} /$ week, no dose $>162 \mathrm{mg} /$ week post-index

k. tofacitinib (oral): no dose $\geq 20 \mathrm{mg} /$ day post-index

3. No new conventional synthetic DMARD: no new claim for leflunomide, methotrexate, sulfasalazine, or hydroxychloroquine post-index in patients who did not have any pre-index claims for that drug

4. No targeted DMARD switch: no claim for a TNFi or nonTNFi post-index that was different from the index drug

5. No new/increased oral glucocorticoid: for patients with no pre-index oral glucocorticoids, $<30$ days of oral glucocorticoids between the index dates and 90 days post-index; for patients with pre-index oral glucocorticoids, a cumulative post-index dose within $120 \%$ of the cumulative pre-index dose

6. Fewer than 2 intra-articular injections: administration of glucocorticoid injections on more than one calendar day was prohibited

Pairwise $P$-values for TNFi cyclers vs non-TNFi switchers were calculated by Student's $t$-test for continuous variables and chi-square test for categorical variables. To evaluate the potential effects of baseline differences between the cohorts on treatment outcomes, multivariable logistic models were used to calculate odds ratio (OR), including 95\% confidence intervals and $P$-values for treatment switching, persistence, and effectiveness. Statistical significance was defined as a $P$-value of $<0.05$. In addition to study cohort, other variables in the multivariable analyses were age, sex, plan type, index year, geographic region, rural/urban, hydroxychloroquine pre-index, leflunomide pre-index, methotrexate pre-index, sulfasalazine pre-index, $>1$ vs 1 TNFi or non-TNFi pre-index, total health care expenditures pre-index, RA-related expenditures preindex, number of office visits pre-index, and PDC for all RA medications pre-index. The variable for prior TNFi or non-TNFi therapy used any pre-index claim without a time restriction; the other pre-index variables used a 12-month pre-index period.

\section{Results}

\section{Characteristics of targeted DMARD switchers}

Of the 6,945 patients who switched therapy on the index date and met all the study selection criteria (Figure 1), 5,020 (72.3\%) were TNFi cyclers and 1,925 (27.7\%) were non-TNFi switchers. Most patients (81.7\%) were females, mean age was 49.9 years, mean Deyo-Charlson Comorbidity Index score was 1.4, and 


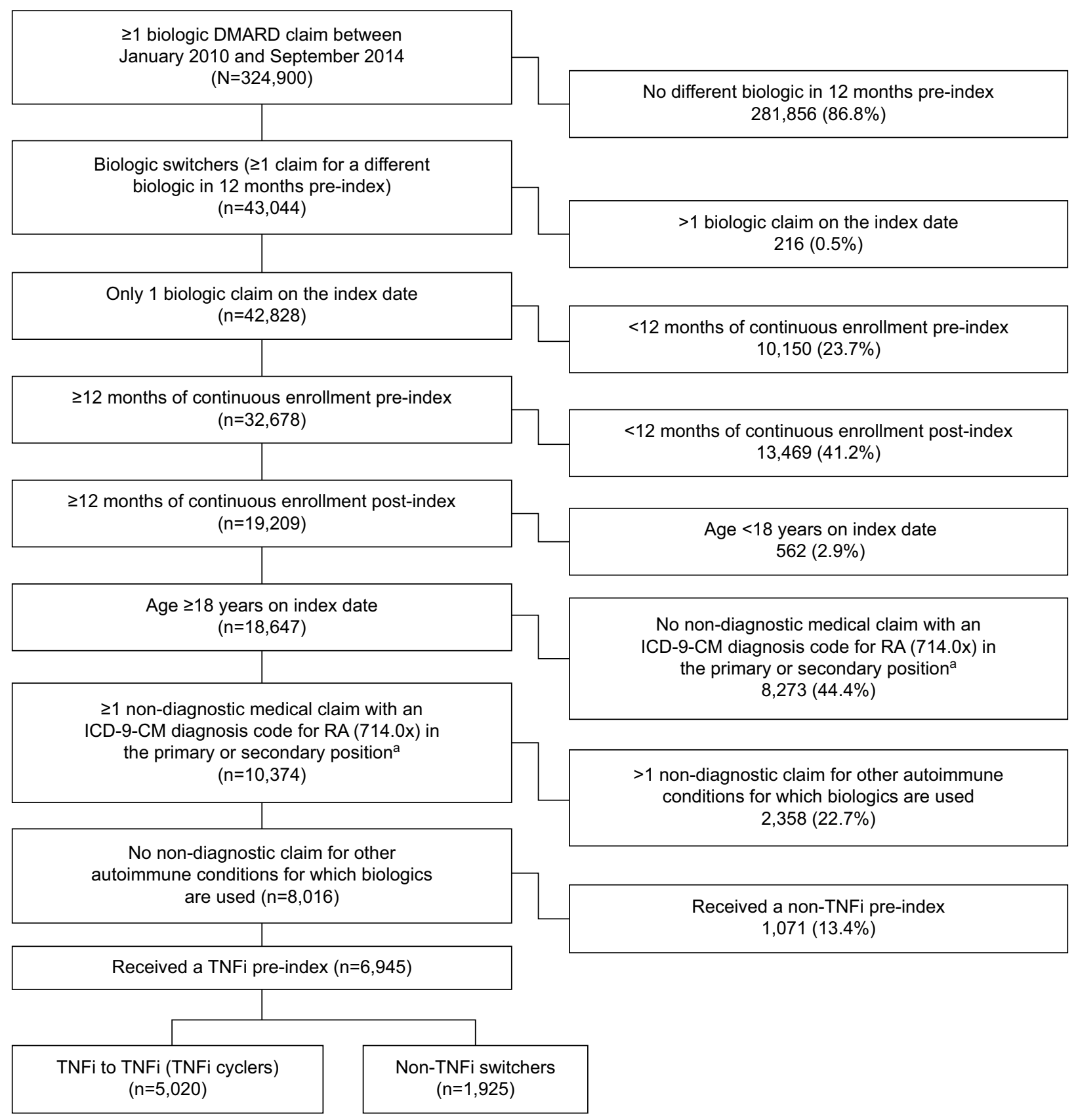

Figure I Study sample selection.

Note: aln the 12-month pre-index period or the first 30 days post-index.

Abbreviations: DMARD, disease-modifying antirheumatic drug; ICD-9-CM, International Classification of Diseases, Ninth Revision, Clinical Modification; RA, rheumatoid arthritis; TNFi, tumor necrosis factor inhibitor.

$6,374(91.8 \%)$ patients received etanercept, adalimumab, or infliximab before they switched to a different drug on the index date (Table 1). Most patients (92.4\%) had received only one targeted DMARD at any time pre-index, including 94.2\% of TNFi cyclers and $87.7 \%$ of non-TNFi switchers (Table 1 ).

\section{Switching therapy again after the index switch}

Overall, 1,231 (17.7\%) and 2,310 (33.3\%) patients switched therapy again within 6 and 12 months, respectively.
Non-TNFi switchers were significantly less likely than TNFi cyclers to switch therapy again within 6 months $(13.2 \%$ vs $19.5 \% ; P<0.001)$ or within 12 months $(29.7 \%$ vs $34.6 \%$; $P<0.001$; Figure 2). In the multivariable analyses for switching again within 6 months (Supplementary materials) or within 12 months (Supplementary materials), which were adjusted for other patient characteristics, non-TNFi switchers were $41 \%$ less likely than TNFi cyclers to switch again within 6 months (OR: $0.593 ; P<0.001)$ and $24 \%$ less likely to switch again within 12 months (OR: $0.762 ; P<0.001)$. 
Table I Demographic and clinical characteristics of targeted DMARD switchers

\begin{tabular}{|c|c|c|c|}
\hline & All patients $(\mathrm{N}=6,945)$ & TNFi cyclers $(n=5,020)$ & Non-TNFi switchers $(n=I, 925)$ \\
\hline Age (years), mean \pm SD & $49.9 \pm 9.6$ & $49.6 \pm 9.7$ & $50.9 \pm 9.3$ \\
\hline Female, n (\%) & $5,673(81.7)$ & $4,058(80.8)$ & $1,615(83.9)$ \\
\hline $\mathrm{DCCl}$, mean $\pm \mathrm{SD}$ & $1.4 \pm 0.8$ & $1.4 \pm 0.8$ & $1.5 \pm 0.9$ \\
\hline \multicolumn{4}{|l|}{ Prior targeted DMARD, n (\%) } \\
\hline Adalimumab & $2,188(31.5)$ & $\mathrm{I}, 648(32.8)$ & $540(28.1)$ \\
\hline Certolizumab pegol & $213(3.1)$ & $121(2.4)$ & $92(4.8)$ \\
\hline Etanercept & $3,200(46.1)$ & $2,568(51.2)$ & $632(32.8)$ \\
\hline Golimumab IV & $0(0.0)$ & $0(0.0)$ & $0(0.0)$ \\
\hline Golimumab SC & $358(5.2)$ & $257(5.1)$ & $101(5.2)$ \\
\hline Infliximab & $986(14.2)$ & $426(8.5)$ & $560(29.1)$ \\
\hline \multicolumn{4}{|c|}{ No of prior targeted DMARDs received at any time pre-index, $n(\%)^{\mathrm{a}}$} \\
\hline One & $6,418(92.4)$ & $4,729(94.2)$ & $\mathrm{I}, 689(87.7)$ \\
\hline Two & $479(6.9)$ & $27 \mid(5.4)$ & $208(10.8)$ \\
\hline Three or more & $48(0.7)$ & $20(0.4)$ & $28(1.5)$ \\
\hline \multicolumn{4}{|c|}{ Prior conventional synthetic DMARD use, $\mathrm{n}(\%)$} \\
\hline Hydroxychloroquine & $1,578(22.7)$ & $\mathrm{I}, 173(23.4)$ & $405(21.0)$ \\
\hline Leflunomide & $1,151(16.6)$ & $816(16.3)$ & $335(17.4)$ \\
\hline Methotrexate & $3,863(55.6)$ & $2,864(57.1)$ & $999(51.9)$ \\
\hline Sulfasalazine & $535(7.7)$ & $394(7.8)$ & $14 \mid(7.3)$ \\
\hline \multicolumn{4}{|c|}{ Most common comorbid conditions, $\mathrm{n}(\%)$} \\
\hline Hypertension & $1,373(19.8)$ & $924(18.4)$ & $449(23.3)$ \\
\hline Benign hypertension & $1,085(15.6)$ & $75 I(15.0)$ & $334(17.4)$ \\
\hline Pain in limb & $979(14.1)$ & $688(13.7)$ & $291(15.1)$ \\
\hline Malaise and fatigue & $904(13.0)$ & $643(12.8)$ & $261(13.6)$ \\
\hline Acute sinusitis & $907(13.1)$ & $662(13.2)$ & $245(12.7)$ \\
\hline \multicolumn{4}{|c|}{ RA-related health care utilization, mean $\pm S D$} \\
\hline No. of outpatient office visits & $5.3 \pm 3.3$ & $5.3 \pm 3.1$ & $5.9 \pm 3.5$ \\
\hline No. of pharmacy prescriptions & $10.2 \pm 6.8$ & $11.3 \pm 6.6$ & $10.6 \pm 6.5$ \\
\hline
\end{tabular}

Note: aNumber of prior targeted DMARDs included any pre-index claim, without a time restriction.

Abbreviations: DCCl, Deyo-Charlson Comorbidity Index; DMARD, disease-modifying antirheumatic drug; IV, intravenous; RA, rheumatoid arthritis; SC, subcutaneous; $\mathrm{SD}$, standard deviation; TNFi, tumor necrosis factor inhibitor.

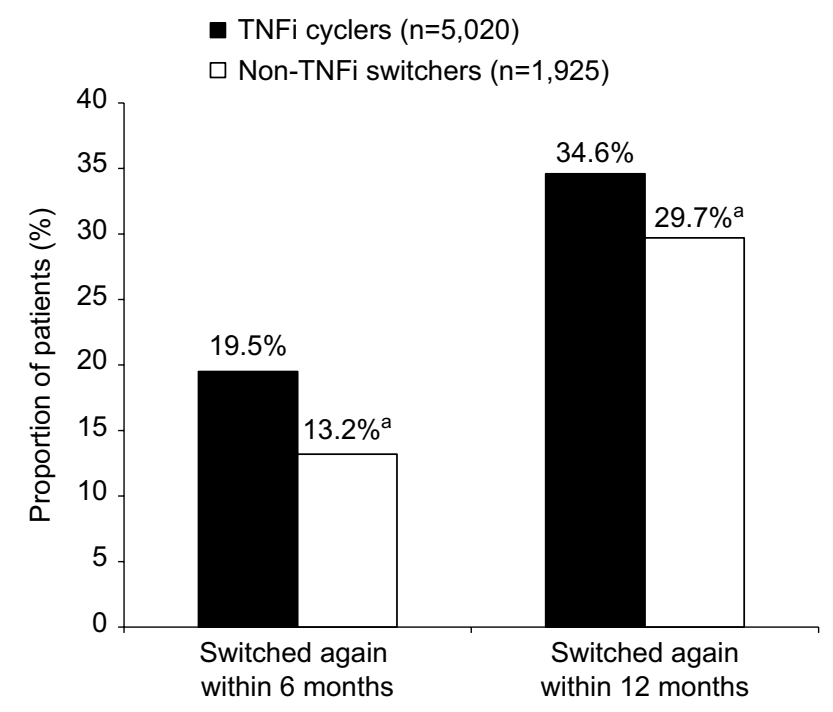

Figure 2 Proportion of targeted DMARD switchers who switched therapy again. Note: ${ }^{a}<0.001$ compared with TNFi cyclers.

Abbreviations: DMARD, disease-modifying antirheumatic drug; TNFi, tumor necrosis factor inhibitor.

\section{Treatment persistence after the index switch}

Non-TNFi switchers had significantly higher treatment persistence than TNFi cyclers, both for the mean duration of persistence ( 293.3 vs 279.6 days; $P<0.001)$ and for the proportion of patients who were persistent at 12 months after the index switch $(61.8 \%$ vs $58.2 \% ; P<0.001$; Table 2$)$. In the multivariable model that was adjusted for baseline demographic and clinical characteristics (Supplementary materials), non-TNFi switchers were $21 \%$ more likely than TNFi cyclers to be persistent at 12 months (OR: 1.206; $P=0.001$ ).

\section{Treatment effectiveness according to algorithm}

Overall, $24.8 \%$ of patients satisfied all six of the treatment effectiveness algorithm criteria during the 12 months after the initial switch in therapy (Table 3 ). The effectiveness rate per algorithm was significantly higher for non-TNFi switchers than TNFi cyclers $(27 \%$ vs $24 \% ; P=0.011)$. Non-TNFi switchers were significantly more likely than TNFi cyclers 
Table 2 Treatment persistence after the index switch

\begin{tabular}{|c|c|c|c|c|}
\hline Treatment persistence & All patients $(\mathrm{N}=6,945)$ & TNFi cyclers $(n=5,020)$ & Non-TNFi switchers $(n=I, 925)$ & $\boldsymbol{P}$ \\
\hline Mean \pm SD duration (days) & $283.4 \pm I \mid 4.8$ & $279.6 \pm 116.8$ & $293.3 \pm 109.1$ & $<0.00 I^{a}$ \\
\hline Persistent at 12 months, $\mathrm{n}(\%)$ & $4,110(59.2)$ & $2,920(58.2)$ & $\mathrm{I}, 190(61.8)$ & $<0.00 I^{\mathrm{b}}$ \\
\hline
\end{tabular}

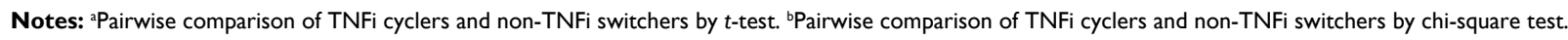

Abbreviations: SD, standard deviation; TNFi, tumor necrosis factor inhibitor.

Table 3 Treatment effectiveness for the 12 months after the index switch, using the claims-based algorithm

\begin{tabular}{|c|c|c|c|c|}
\hline \multirow[t]{2}{*}{ Algorithm criterion } & \multicolumn{3}{|c|}{ Patients achieving the criterion, $\mathbf{n}(\%)$} & \multirow[t]{2}{*}{$P^{\mathbf{a}}$} \\
\hline & All patients $(\mathrm{N}=6,945)$ & TNFi cyclers $(n=5,020)$ & Non-TNFi switchers $(n=I, 925)$ & \\
\hline Satisfied all six algorithm criteria & $\mathrm{I}, 724(24.8)$ & $\mathrm{I}, 205(24.0)$ & $519(27.0)$ & 0.011 \\
\hline Adherent & $2,809(40.4)$ & $2,006(40.0)$ & $803(41.7)$ & 0.182 \\
\hline No increase in the targeted & $6,257(90.1)$ & $4,429(88.2)$ & $\mathrm{I}, 828(95.0)$ & $<0.001$ \\
\hline \multicolumn{5}{|l|}{ DMARD dose } \\
\hline No new conventional synthetic & $5,901(85.0)$ & $4,253(84.7)$ & $\mathrm{I}, 648(85.6)$ & 0.353 \\
\hline \multicolumn{5}{|l|}{ DMARD } \\
\hline No targeted DMARD switch & $4,635(66.7)$ & $3,282(65.4)$ & $1,353(70.3)$ & $<0.001$ \\
\hline No new/increased glucocorticoid & $5,935(85.5)$ & $4,304(85.7)$ & $\mathrm{I}, 63 \mathrm{I}(84.7)$ & 0.285 \\
\hline Less than two intra-articular & $6,294(90.6)$ & $4,549(90.6)$ & $\mathrm{I}, 745(90.6)$ & 0.968 \\
\hline injections & & & & \\
\hline
\end{tabular}

Note: aPairwise comparison of TNFi cyclers and non-TNFi switchers by chi-square test.

Abbreviations: DMARD, disease-modifying antirheumatic drug; TNFi, tumor necrosis factor inhibitor.

to achieve the effectiveness algorithm criteria for no increase in the targeted DMARD dose $(95 \%$ vs $88.2 \% ; P<0.001)$ and no switch to another targeted DMARD (70.3\% vs $65.4 \%$; $P<0.001)$. Achievement rates for other algorithm criteria were not significantly different between non-TNFi switchers and TNFi cyclers. In the multivariable analysis of treatment effectiveness that adjusted for other patient characteristics, non-TNFi switchers were $20 \%$ more likely than TNFi cyclers (OR: $1.195 ; P=0.006)$ to achieve all effectiveness algorithm criteria (Supplementary materials).

\section{Discussion}

This claims-based analysis examined treatment patterns and treatment effectiveness for 6,945 commercially insured patients with RA across the US after they switched therapy from a TNFi either to another TNFi (TNFi cyclers) or to a non-TNFi (non-TNFi switchers). Nearly three-quarter of these real-world patients were TNFi cyclers, which is consistent with previous evidence that a majority of patients in clinical practice are TNFi cyclers instead of non-TNFi switchers..$^{5-11}$ However, in this study, non-TNFi switchers had better outcomes than TNFi cyclers. Recognizing that the absolute differences were small, non-TNFi switchers were significantly more likely to be persistent on the new therapy, significantly less likely to switch to another therapy within 6 or 12 months after the initial switch, and significantly more likely to be effectively treated according to a claims-based effectiveness algorithm. These results suggest that patients who need to discontinue TNFi therapy because of ineffectiveness or intolerability are more likely to benefit from switching to a non-TNFi instead of cycling to another TNFi.

Because the analyses were retrospective and not randomized, the patients who switched to a non-TNFi may have had background characteristics that made them more likely to be persistent on therapy and more likely to achieve the algorithm criteria for effectiveness than patients who switched to a TNFi. To address this possibility, multivariable analyses were conducted that included variables for baseline characteristics and other measures of disease severity, some of which (eg, prior methotrexate use for 6-month switching rates and effectiveness) were also statistically significant predictors for outcomes. After adjusting for these possible factors, differences for treatment persistence, switching, and effectiveness continued to significantly favor non-TNFi switchers compared to TNFi cyclers. In the multivariable analyses, non-TNFi switching was associated with $\sim 20 \%-25 \%$ relative improvement in each of the 12-month outcomes relative to TNFi cycling.

Another real-world study recently examined treatment patterns among patients who initiated treatment with a TNFi in 2011 or 2012 , including 764 patients who switched to a different targeted DMARD. ${ }^{7}$ The probability of switching again was significantly greater for TNFi cyclers compared with non-TNFi switchers (37\% vs 28\%; $P=0.031)$. Discontinuation rates were $14 \%$ in each treatment group, and $49 \%$ of TNFi cyclers and $58 \%$ of non-TNFi switchers continued 
therapy without a treatment gap of $>180$ days. In this study, similar rates were observed for these cohorts for switching again and treatment persistence. Although both studies used the Truven Health Analytics MarketScan Research database, the previous study included patients who received a TNFi and then switched to a different therapy in 2011 or 2012. This study included more recent data (switches that occurred between January 1, 2010 and September 30, 2014, with follow-up data through September 30, 2015) to examine current treatment patterns, including greater use of newer agents.

This study examined not only treatment persistence but also treatment effectiveness after TNFi cycling and nonTNFi switching. Estimates of effectiveness in this retrospective claims-based analysis were consistent with the results from two prospective studies that compared TNFi cycling vs switching to the non-TNFi rituximab. ${ }^{16,17}$ In these studies, switching from a TNFi to a non-TNFi improved clinical outcomes more effectively than TNFi cycling. However, both of the studies were observational, not interventional. Thus, like this retrospective analysis, both of the studies were subject to the potential limitation of selection bias, which may lead a clinician to choose non-TNFi switching vs TNFi cycling in a given patient. Additionally, the benefits in each observational study appeared to be limited to subgroups of patients. One observational study reported that clinical improvement with switching to a non-TNFi relative to TNFi cycling occurred in the subgroup of patients who discontinued the initial TNFi because of inefficacy, but not among those who switched therapy because of intolerance. ${ }^{16}$ The other study reported that the clinical benefits of switching to a non-TNFi were observed vs TNFi cyclers who switched to adalimumab or infliximab, but not when TNFi cycling to etanercept was included in the comparison. ${ }^{17} \mathrm{~A}$ recent presentation of the results from a randomized, interventional study of 292 patients with an inadequate response to the first TNFi reported that switching to a non-TNFi resulted in significantly better efficacy than TNFi cycling, and the observed superiority was consistent over time and across outcome criteria. ${ }^{36}$

Treatment effectiveness in this study was analyzed by the application of a validated algorithm ${ }^{29}$ to medical and pharmacy claims. The claims-based algorithm was initially developed and validated for the biologic DMARDs abatacept (intravenous only), adalimumab, etanercept, and infliximab. This analysis also applied the algorithm to the newer therapies certolizumab pegol, golimumab, tocilizumab, and tofacitinib, as well as subcutaneous administration of abatacept.
Although these therapies were not included in the original validation, other recent studies that used similar methods to apply the algorithm to newer therapies ${ }^{4,31-33}$ had similar results for relative treatment effectiveness compared with studies that did not include these newer therapies. ${ }^{30,35}$

This analysis pooled the results for all TNFis into one cohort and for all non-TNFis into the other cohort. Additional research would be required to establish whether an individual TNFi or individual non-TNFi is associated with significantly different treatment persistence and treatment effectiveness in real-world settings. Although some of the absolute differences were relatively small between TNFi cyclers and non-TNFi switchers, multivariable analyses consistently showed that the adjusted differences were $\geq 20 \%$ for the odds of treatment persistence, switching again, and treatment effectiveness. This difference in outcomes is likely to be clinically meaningful given the high frequency with which RA patients switch therapy in clinical practice. ${ }^{5-11}$ The reasons for discontinuation of the prior TNFi were not recorded in the claims, and thus, they were not analyzed in this study.

\section{Conclusion}

On the basis of this claims-based analysis of commercially insured patients in the US, it appears that non-TNFi switchers are more likely than TNFi cyclers to persist on the new therapy, less likely to switch again, and more likely to achieve treatment effectiveness after switching. These results support switching to a non-TNFi after TNFi treatment failure in patients with RA.

\section{Acknowledgments}

The authors thank George J. Joseph, PhD, MS, for his contributions to the study design and analyses. This work was sponsored by Regeneron Pharmaceuticals, Inc. and Sanofi US. Jonathan Latham of PharmaScribe, LLC received financial support from Regeneron Pharmaceuticals, Inc. and Sanofi US to assist the authors with the preparation and submission of the manuscript.

\section{Disclosure}

Bonafede and McMorrow: employees of Truven Health Analytics, an IBM Company, that received a research contract from Sanofi and Regeneron to conduct this study. Curtis: Research grants and honoraria from UCB, Janssen, Corrona, Amgen, Pfizer, BMS, and Crescendo. Mahajan: employee of Sanofi. Chen: employee and stockholder of Regeneron Pharmaceuticals, Inc. The authors report no other conflicts of interest in this work. 


\section{References}

1. Saag KG, Teng GG, Patkar NM, et al. American College of Rheumatology 2008 recommendations for the use of nonbiologic and biologic disease-modifying antirheumatic drugs in rheumatoid arthritis. Arthritis Rheum. 2008;59(6):762-784.

2. Singh JA, Furst DE, Bharat A, et al. 2012 update of the 2008 American College of Rheumatology recommendations for the use of disease-modifying antirheumatic drugs and biologic agents in the treatment of rheumatoid arthritis. Arthritis Care Res (Hoboken). 2012;64(5):625-639.

3. Singh JA, Saag KG, Bridges SL Jr, et al. 2015 American College of Rheumatology Guideline for the treatment of rheumatoid arthritis. Arthritis Rheumatol. 2016;68(1):1-26.

4. Bonafede M, Johnson BH, Princic N, Shah N, Harrison DJ. Cost per patient-year in response using a claims-based algorithm for the 2 years following biologic initiation in patients with rheumatoid arthritis. J Med Econ. 2015;18(5):376-389.

5. Bonafede M, Fox KM, Watson C, Princic N, Gandra SR. Treatment patterns in the first year after initiating tumor necrosis factor blockers in real-world settings. Adv Ther. 2012;29(8):664-674.

6. Soliman MM, Hyrich KL, Lunt M, et al; British Society for Rheumatology Biologics Register. Rituximab or a second anti-tumor necrosis factor therapy for rheumatoid arthritis patients who have failed their first anti-tumor necrosis factor therapy? Comparative analysis from the British Society for Rheumatology Biologics Register. Arthritis Care Res (Hoboken). 2012;64(8):1108-1115.

7. Harnett J, Wiederkehr D, Gerber R, Gruben D, Koenig A, Bourret J. Real-world evaluation of TNF-inhibitor utilization in rheumatoid arthritis. J Med Econ. 2016;19(2):91-102.

8. Harrold LR, Reed GW, Magner R, et al. Comparative effectiveness and safety of rituximab versus subsequent anti-tumor necrosis factor therapy in patients with rheumatoid arthritis with prior exposure to anti-tumor necrosis factor therapies in the United States Corrona registry. Arthritis Res Ther. 2015;17:256.

9. Baser O, Ganguli A, Roy S, Xie L, Cifaldi M. Impact of switching from an initial tumor necrosis factor inhibitor on health care resource utilization and costs among patients with rheumatoid arthritis. Clin Ther. 2015;37(7):1454-1465.

10. Bergman M, De G, Ganguli A, Signorovitch J, Bao Y. Assessment of income growth in patients with rheumatoid arthritis treated with antitumor necrosis factor therapy. J Med Econ. 2015;18(1):37-44.

11. Chatzidionysiou K, van Vollenhoven RF. Rituximab versus anti-TNF in patients who previously failed one TNF inhibitor in an observational cohort. Scand J Rheumatol. 2013;42(3):190-195.

12. Haraoui B, Keystone EC, Thorne JC, et al. Clinical outcomes of patients with rheumatoid arthritis after switching from infliximab to etanercept. J Rheumatol. 2004;31(12):2356-2359.

13. Buch MH, Bingham SJ, Bejarano V, et al. Therapy of patients with rheumatoid arthritis: outcome of infliximab failures switched to etanercept. Arthritis Rheum. 2007;57(3):448-453.

14. Smolen JS, Kay J, Doyle MK, et al. Golimumab in patients with active rheumatoid arthritis after treatment with tumour necrosis factor alpha inhibitors (GO-AFTER study): a multicentre, randomised, double-blind, placebo-controlled, phase III trial. Lancet. 2009;374(9685):210-221.

15. Bombardieri S, Ruiz AA, Fardellone P, et al. Effectiveness of adalimumab for rheumatoid arthritis in patients with a history of TNFantagonist therapy in clinical practice. Rheumatology. 2007;46(7): 1191-1199.

16. Emery P, Gottenberg JE, Rubbert-Roth A, et al. Rituximab versus an alternative TNF inhibitor in patients with rheumatoid arthritis who failed to respond to a single previous TNF inhibitor: SWITCH-RA, a global, observational, comparative effectiveness study. Ann Rheum Dis. 2015;74(6):979-984.

17. Gomez-Reino JJ, Maneiro JR, Ruiz J, et al; MIRAR Study Group. Comparative effectiveness of switching to alternative tumour necrosis factor (TNF) antagonists versus switching to rituximab in patients with rheumatoid arthritis who failed previous TNF antagonists: the MIRAR Study. Ann Rheum Dis. 2012;71(11):1861-1864.
18. Kim HL, Lee MY, Park SY, et al. Comparative effectiveness of cycling of tumor necrosis factor-alpha (TNF-alpha) inhibitors versus switching to non-TNF biologics in rheumatoid arthritis patients with inadequate response to TNF-alpha inhibitor using a Bayesian approach. Arch Pharm Res. 2014;37(5):662-670.

19. Malottki K, Barton P, Tsourapas A, et al. Adalimumab, etanercept, infliximab, rituximab and abatacept for the treatment of rheumatoid arthritis after the failure of a tumour necrosis factor inhibitor: a systematic review and economic evaluation. Health Technol Assess. 2011; 15(14):1-278.

20. Genovese MC, Fleischmann R, Kivitz AJ, et al. Sarilumab plus methotrexate in patients with active rheumatoid arthritis and inadequate response to methotrexate: results of a phase III study. Arthritis Rheumatol. 2015;67(6):1424-1437.

21. Fleischmann R, Castelar-Pinheiro G, Brzezicki J, et al. Efficacy and Safety of sarilumab in combination with csDMARDs in patients with active rheumatoid arthritis who were inadequate responders or intolerant of anti-TNF-i therapy: results from a phase 3 study [abstract]. Arthritis Rheumatol. 2015;67(Suppl 10):Abstract 970.

22. Smolen JS, Weinblatt ME, Sheng S, Zhuang Y, Hsu B. Sirukumab, a human anti-interleukin-6 monoclonal antibody: a randomised, 2-part (proof-of-concept and dose-finding), phase II study in patients with active rheumatoid arthritis despite methotrexate therapy. Ann Rheum Dis. 2014;73(9):1616-1625.

23. Keystone EC, Taylor PC, Drescher E, et al. Safety and efficacy of baricitinib at 24 weeks in patients with rheumatoid arthritis who have had an inadequate response to methotrexate. Ann Rheum Dis. 2015;74(2):333-340.

24. Tanaka Y, Emoto K, Cai Z, et al. Efficacy and safety of baricitinib in Japanese patients with active rheumatoid arthritis receiving background methotrexate therapy: a 12-week, double-blind, randomized placebocontrolled Study. J Rheumatol. 2016;43(3):504-511.

25. Genovese MC, Kremer J, Zamani O, et al. Baricitinib in patients with refractory rheumatoid arthritis. $N$ Engl J Med. 2016;374(13): 1243-1252.

26. Reichert JM. Antibodies to watch in 2016. MAbs. 2016;8(2):197-204.

27. Yamaoka K. Janus kinase inhibitors for rheumatoid arthritis. Curr Opin Chem Biol. 2016;32:29-33.

28. Rothwell PM. External validity of randomised controlled trials: "to whom do the results of this trial apply?" Lancet. 2005;365(9453):82-93.

29. Curtis JR, Baddley JW, Yang S, et al. Derivation and preliminary validation of an administrative claims-based algorithm for the effectiveness of medications for rheumatoid arthritis. Arthritis Res Ther. 2011;13(5):R155.

30. Curtis JR, Chastek B, Becker L, et al. Further evaluation of a claimsbased algorithm to determine the effectiveness of biologics for rheumatoid arthritis using commercial claims data. Arthritis Res Ther. 2013;15(2):404.

31. Curtis JR, Schabert VF, Harrison DJ, et al. Estimating effectiveness and cost of biologics for rheumatoid arthritis: application of a validated algorithm to commercial insurance claims. Clin Ther. 2014;36(7):996-1004.

32. Curtis JR, Schabert VF, Yeaw J, et al. Use of a validated algorithm to estimate the annual cost of effective biologic treatment for rheumatoid arthritis. J Med Econ. 2014;17(8):555-566.

33. Curtis JR, Chastek B, Becker L, et al. Cost and effectiveness of biologics for rheumatoid arthritis in a commercially insured population. J Manag Care Spec Pharm. 2015;21(4):318-329.

34. Yun H, Xie F, Delzell E, et al. The comparative effectiveness of biologics among older adults and disabled rheumatoid arthritis patients in the Medicare population. Br J Clin Pharmacol. 2015;80(6):1447-1457.

35. Oladapo A, Barner JC, Lawson KA, et al. Medication effectiveness with the use of tumor necrosis factor inhibitors among Texas Medicaid patients diagnosed with rheumatoid arthritis. JManag Care Spec Pharm. 2014;20(7):657-667.

36. Gottenberg J, Brocq O, Perdriger A, et al. In the multicenter randomized controlled rotation or change trial, a non-TNF targeted therapy has a higher efficacy than a second anti-TNF at 3, 6 and 12 months [abstract]. Arthritis Rheumatol. 2015;67(Suppl 10):Abstract 3110. 
ClinicoEconomics and Outcomes Research is an international, peerreviewed open-access journal focusing on health technology assessment, pharmacoeconomics and outcomes research in the areas of diagnosis, medical devices, and clinical, surgical and pharmacological intervention. The economic impact of health policy and health systems organization also constitute important areas of coverage. The manuscript management system is completely online and includes a very quick and fair peer-review system, which is all easy to use. Visit http://www.dovepress.com/testimonials.php to read real quotes from published authors.

Submit your manuscript here: https://www.dovepress.com/clinicoeconomics-and-outcomes-research-journal 